\title{
INTERthesis
}

Revista

Internacional

Interdisciplinar INTERthesis

\section{O DESENVOLVIMENTO NO CONTEXTO DA SOCIEDADE DA INFORMAÇÃO E O ACESSO À INTERNET COMO DIREITO HUMANO NA ORDEM INTERNACIONAL}

\author{
Fausto Gonçalves Cintra ${ }^{1}$ \\ Carla Aparecida Arena Ventura ${ }^{2}$
}

\section{Resumo:}

O presente artigo propõe uma reflexão teórica acerca da questão do desenvolvimento na sociedade da informação, comparando suas categorias e objetos centrais. A partir daí, verifica, no âmbito das organizações internacionais, o que se entende por desenvolvimento e as respectivas implicações na sociedade da informação. Avalia as transformações processadas no direito humano à informação na dinâmica da evolução tecnológica, que conduziram à emergência do direito de acesso à Internet e de seu potencial reconhecimento como direito humano. Examina, a seguir, os argumentos a favor e contra tal reconhecimento e as suas respectivas implicações. Considera, por fim, que o estágio atual é inconclusivo, embora caminhe a passos firmes no sentido de acolher o direito de acesso à Internet como direito humano; contudo, pondera que se devesse pensar em garantir acesso à informação de forma ampla, por quaisquer meios.

Palavras-chave: Sociedade da informação. Desenvolvimento. Acesso à informação. Direito de acesso à Internet. Direitos humanos. Organizações internacionais.

\section{INTRODUÇÃO}

Vivemos (n)a sociedade da informação. Nela, produzimos, compartilhamos, acessamos e consumimos informação a todo instante, na qualidade de produto como qualquer outro. Nesse contexto, a Internet se fez de tal modo indispensável, a ponto de se constituir tecnologia básica sobre a qual a sociedade em redes se organiza, representando, para a Era da Informação, o que foi a eletricidade para a Era Industrial (CASTELLS, 2005). Assim, não é difícil imaginar que, em algum

\footnotetext{
${ }^{1}$ Mestrando do Programa de Pós-Graduação em Desenvolvimento Regional do Centro Universitário de Franca, Franca, São Paulo, SP, Brasil. E-mail: goncin@gmail.com

2 Doutora em Administração pela Universidade de São Paulo. Livre-docente na Escola de Enfermagem de Ribeirão Preto da Universidade de São Paulo, professora associado na mesma escola e universidade, São Paulo, SP, Brasil. Professora do Programa de Pós-Graduação em Desenvolvimento Regional do Centro Universitário de Franca, São Paulo, SP, Brasil. E-mail: caaventu@gmail.com
} 
momento, aquele que não tiver acesso à Grande Rede, e, consequentemente, à informação, tornar-se-á de todo um pária.

O presente artigo pretende lançar algumas luzes sobre essa questão, tendo por perspectiva o desenvolvimento em suas múltiplas dimensões e, a partir da perspectiva dos organismos internacionais, determinar se o acesso à Internet preenche os quesitos indispensáveis para seu reconhecimento como direito humano fundamental.

Para tanto, inicia contextualizando o desenvolvimento na sociedade da informação, comparando suas categorias e objetos centrais. A partir daí, verifica, no âmbito do Direito Internacional, o que se entende por desenvolvimento e as respectivas implicações na sociedade da informação. Em seguida, avalia as transformações processadas no direito humano à informação na dinâmica da evolução tecnológica, que conduziram à emergência do direito de acesso à Internet e de seu potencial reconhecimento como direito humano. Examina, também, os argumentos a favor e contra tal reconhecimento e as suas respectivas implicações. Considera, por fim, que o estágio atual é inconclusivo, embora caminhe a passos firmes no sentido de acolher o direito de acesso à Internet como direito humano; contudo, pondera que se devesse pensar em garantir acesso à informação de forma ampla, por quaisquer meios.

\section{KARVALICS E AS CATEGORIAS BÁSICAS DA SOCIEDADE DA INFORMAÇÃO}

A expressão "sociedade da informação" tem sido utilizada, não exclusivamente, para denominar a atual conjuntura social, econômica, cultural e política na qual o mundo todo está inserido, em maior ou menor grau. Esse termo, segundo o estudo de Karvalics (2007), foi cunhado no contexto das ciências sociais japonesas (como joho shakai ou johoka shakai), no início da década de 1960, por Kisho Kurokawa, arquiteto, e Tudao Umesao, antropólogo e historiador. Argumentase, também, que a ideia (mas não a expressão exata) é devida a Machlup (1962). $\mathrm{Na}$ década seguinte, a locução information society chegou à literatura científica de língua inglesa, integrando-se a outras expressões então já consagradas, tais como post-industrial society e white collar revolution, na descrição da mesma realidade. 
Independentemente da denominação que se dê ao fenômeno, seu traço mais marcante é a posição central que a informação ocupa nessa sociedade. Essa condição transparece em múltiplos aspectos da vida humana, aos quais Karvalics (2007), em trabalho de síntese literária, denominou "categorias básicas". O esquema, divisado pelo autor e transcrito no Quadro 1, tem a vantagem de oferecer, para cada uma das categorias básicas descritas, uma métrica e, para a maior parte delas, também um ponto decisivo de irreversibilidade, e, ainda, uma série de metáforas - expressões que despontam, particularmente na mídia, para descrever a categoria. Ao se analisar uma sociedade em particular (seja esta a de um continente, a de um país, a de uma região, etc., conforme o recorte adotado), utilizando o método proposto, é possível aferir o quanto essa sociedade, em relação a cada uma de suas categorias básicas, já está inserida na grande sociedade da informação, em escala mundial. Porém, é preciso ressalvar que, no estágio atual de desenvolvimento, nenhuma sociedade particular cumpre simultaneamente as métricas de todas as categorias; dito de outra forma, não se chegou ainda à plenitude da sociedade da informação entrevista por Karvalics.

Quadro 1 Síntese das categorias básicas da sociedade da informação, sua mensurabilidade e suas metáforas

\begin{tabular}{|c|c|c|}
\hline Categoria básica & Medida e "ponto decisivo" & Metáforas \\
\hline $\begin{array}{l}\text { (1) Produção } \\
\text { (transformação) }\end{array}$ & $\begin{array}{l}\text { A proporção de empresas que tomam parte no } \\
\text { setor de produtos de informação e conhecimento } \\
\text { em relação a outros setores (predomínio relativo: } \\
\text { quando constitui o setor predominante; predomínio } \\
\text { absoluto: quando o setor sozinho produz mais de } \\
50 \% \text {, ou seja, é maior que todos os outros setores } \\
\text { somados) }\end{array}$ & $\begin{array}{l}\text { indústria da informação, } \\
\text { indústria do } \\
\text { conhecimento, indústria } \\
\text { da informação e do } \\
\text { conhecimento, } \\
\text { economia da } \\
\text { informação, economia } \\
\text { do conhecimento, } \\
\text { economia baseada no } \\
\text { conhecimento }\end{array}$ \\
\hline (2) Emprego & $\begin{array}{l}\text { O número e a proporção da força de trabalho } \\
\text { empregada nos setores de informação e } \\
\text { conhecimento em relação a outros setores } \\
\text { (predomínio relativo: quando é o maior setor; } \\
\text { predomínio absoluto: quando o setor sozinho } \\
\text { produz mais de } 50 \% \text {, ou seja, é maior que todos os } \\
\text { outros setores somados) }\end{array}$ & $\begin{array}{l}\text { trabalhadores de } \\
\text { colarinho branco, } \\
\text { trabalhadores da } \\
\text { informação e do } \\
\text { conhecimento, classe } \\
\text { de inteligência, } \\
\text { "intelligentsia" }\end{array}$ \\
\hline (3) Trabalho & $\begin{array}{l}\text { Número de pessoas e em que grau estão } \\
\text { comprometidas "profissionalmente" com atividades } \\
\text { de informação, de acordo com o tipo de trabalho } \\
\text { realizado (percentual mínimo: } 50 \% \text { ) }\end{array}$ & $\begin{array}{l}\text { manipuladores de } \\
\text { símbolos, inteligência, } \\
\text { trabalhador } \\
\text { cerebral/mental }\end{array}$ \\
\hline $\begin{array}{l}\text { (4) Recursos e } \\
\text { tecnologia }\end{array}$ & $\begin{array}{l}\text { Informação e conhecimento figuram como recursos } \\
\text { e formas de capital em adição às formas } \\
\text { tradicionais - as teorias do crescimento e da }\end{array}$ & $\begin{array}{l}\text { capital intelectual, } \\
\text { capital humano, capital } \\
\text { de informação, }\end{array}$ \\
\hline
\end{tabular}




\begin{tabular}{|c|c|c|}
\hline Categoria básica & Medida e "ponto decisivo" & Metáforas \\
\hline & $\begin{array}{l}\text { contabilidade se esforçam para traduzir isso em } \\
\text { números, mas até o momento não há nenhum } \\
\text { algoritmo aceito (no entanto, a contribuição da } \\
\text { tecnologia da informação e do conhecimento para } \\
\text { o crescimento já foi mensurada) }\end{array}$ & $\begin{array}{l}\text { informação corporativa } \\
\text { e bens de } \\
\text { conhecimento }\end{array}$ \\
\hline (5) Renda e riqueza & $\begin{array}{l}\text { O Produto Nacional Bruto em escala nacional, a } \\
\text { renda mensal em escala individual. Não existem } \\
\text { métricas aceitas em relação a valores; além disso, } \\
\text { esses valores variam de acordo com o momento } \\
\text { da adesão à sociedade da informação. } \\
\text { US\$ } 5.000,00 / \text { pessoa/mês era o limite mínimo na } \\
\text { virada dos anos 1960, nos EUA }\end{array}$ & $\begin{array}{l}\text { fartura, Estado de bem- } \\
\text { estar social }\end{array}$ \\
\hline (6) Consumo & $\begin{array}{l}\text { A proporção de informação adquirida e bens } \\
\text { culturais, meios e serviços no total de bens } \\
\text { consumidos por uma pessoa, especialmente no } \\
\text { tocante a conteúdo midiático (percentual mínimo: } \\
33 \% \text { ) }\end{array}$ & $\begin{array}{l}\text { sociedade de consumo } \\
\text { ou sociedade } \\
\text { consumidora, } \\
\text { "prossumidores" } \\
\text { (produtores- } \\
\text { consumidores), } \\
\text { sociedade midiática ou } \\
\text { midiatizada }\end{array}$ \\
\hline $\begin{array}{l}\text { (7) (Nível de) } \\
\text { Educação }\end{array}$ & $\begin{array}{l}\text { Proporção daqueles detentores de qualificação em } \\
\text { nível superior (graduados) na sociedade } \\
\text { (percentual mínimo: } 50 \% \text { ) }\end{array}$ & $\begin{array}{l}\text { sociedade cognitiva, } \\
\text { meritocracia }\end{array}$ \\
\hline (8) Cognição & $\begin{array}{l}\text { Resultados e escalas nas dimensões mensuráveis } \\
\text { da cognição; dimensões microscópicas, distâncias } \\
\text { e escalas astronômicas, combinações genéticas } \\
\text { descobertas, processamento de símbolos, etc. A } \\
\text { escala para tal medição está ainda por ser } \\
\text { desenvolvida }\end{array}$ & $\begin{array}{l}\text { aprendizagem contínua, } \\
\text { revolução científica, } \\
\text { nanoescala, petaescala }\end{array}$ \\
\hline $\begin{array}{l}\text { (9) Método de } \\
\text { administração de } \\
\text { conflitos e técnica de } \\
\text { exercício do poder }\end{array}$ & $\begin{array}{l}\text { Substituição das formas tradicionais de fazer } \\
\text { guerra, colocando conflitos econômicos num } \\
\text { contexto informacional (inteligência de negócios, } \\
\text { inovação competitiva). O "estado de democracia" } \\
\text { da sociedade, tipos e mediadores de controle. Há } \\
\text { alguns métodos usados para medir o "grau" de } \\
\text { democracia }\end{array}$ & $\begin{array}{l}\text { guerra pela informação, } \\
\text { guerra cibernética, } \\
\text { inteligência de } \\
\text { negócios, burocracia, } \\
\text { administração de crises } \\
\text { e revoluções, sociedade } \\
\text { de risco }\end{array}$ \\
\hline $\begin{array}{l}(10) \\
\text { Interconectividade }\end{array}$ & $\begin{array}{l}\text { O grau de conexão mútua (objetivo no caso das } \\
\text { redes telefônicas: disponibilidade acima de } 50 \% \text { ) }\end{array}$ & $\begin{array}{l}\text { sociedade telemática, } \\
\text { sociedade "plugada" }\end{array}$ \\
\hline $\begin{array}{l}\text { (11) Visão de mundo } \\
\text { e enquadramento } \\
\text { lógico }\end{array}$ & $\begin{array}{l}\text { A visão de mundo estática, centrada na energia, foi } \\
\text { substituída por outra centrada na informação? A } \\
\text { escala sistêmica global e a "era do espaço" se } \\
\text { tornaram um nova estrutura para análise e } \\
\text { interpretação? Uma marca característica é a } \\
\text { orientação em direção ao futuro? }\end{array}$ & $\begin{array}{l}\text { aldeia global, } \\
\text { tecnocultura, civilização } \\
\text { da informação }\end{array}$ \\
\hline
\end{tabular}

Fonte: Traduzido e adaptado de Karvalics, 2007, p. 13.

É no plano econômico (categorias 1, 4, 5, 6 e 9) que a condição nuclear da informação se mostra mais patente. Ali, ela assume a função de matéria-prima, não apenas sob a forma de informação para agir sobre uma nova tecnologia (tal como nas revoluções tecnológicas antecedentes), mas, e principalmente, constituindo-se como a própria tecnologia, atuando em proveito de si mesma (CASTELLS, 2005). 
Ao mesmo tempo que se presta como insumo, com frequência, a informação é o próprio produto final a ser comercializado. A inovação constante - em outras palavras, a produção contínua de novos conhecimentos a partir da informação torna-se, muito mais que um diferencial competitivo, um fator crucial para a própria existência das empresas. A fonte informativa primária que subsidia o processo de inovação é o consumidor, do qual se capta o desejo (muitas vezes inconsciente) ou em quem se incute uma necessidade de consumo.

\begin{abstract}
Para a maioria das empresas, a sobrevivência passa pela pesquisa permanente de novas aberturas comerciais que levam à definição de gamas de produtos sempre mais amplos ou diferenciados. A inovação não é mais subordinada apenas à racionalização do trabalho, mas também aos imperativos comerciais. Parece então que a mercadoria pós-industrial é o resultado de um processo de criação que envolve tanto o produtor quanto o consumidor (LAZZARATO; NEGRI, 2001, p. 44).
\end{abstract}

Logo, passa-se a medir o valor agregado de um produto pelo acúmulo de conhecimento nele concentrado. Com isso, a etapa da produção perde importância em favor da comercialização e da financeirização, aumentando consideravelmente o espaço ocupado pelo setor de serviços no conjunto da economia.

A configuração econômica apontada produz seus reflexos no campo das relações de trabalho (categorias 3 e 4). Num passado não muito remoto, saber ler e interpretar textos, bem como efetuar cálculos matemáticos elementares, era o exigido para se viver em harmonia e bem-estar na sociedade. Nos dias atuais, as necessidades de qualificações profissionais e acadêmicas aumentaram notavelmente (LYON apud SILVA, 2011), nos termos da categoria 7. Noutra frente, o acesso à informação, que pressupõe interconectividade (categoria 10), tornou-se o mais drástico fator de discriminação entre países (DE MASI, 2001). De fato, segundo a União Internacional de Telecomunicações (ITU, 2012), ao mesmo tempo em que, nos países desenvolvidos, o mercado de telecomunicações (nomeadamente telefonia e acesso móvel à Internet em banda larga) encontra-se saturado, os países em desenvolvimento sofrem com o alto custo dos equipamentos e conexões e com a baixa qualidade do serviço.

A interseção de todos esses fatores, enfim, passa por um novo modo de olhar o mundo (categoria 11), um grande encruzamento no qual mais uma vez ela - a informação - se faz perpassar, num ponto que já pertenceu à força mecânica e, mais tarde, à energia. 


\section{O DIREITO AO DESENVOLVIMENTO NA SOCIEDADE DA INFORMAÇÃO}

Ubi societas, ibi ius. Os romanos já tinham consciência de que os direitos nascem do seio de uma sociedade, a partir de suas necessidades, num dado tempo e espaço; com isso, tornam-se particulares àquela sociedade. Por conseguinte, é razoável supor que a emergência da sociedade da informação demandou o aparecimento de novos direitos, precisos às novas circunstâncias ou, ao menos, que tenha levado os direitos já existentes a uma nova dimensão. Posto que "os Direitos Humanos formam, atualmente, o único conjunto universalmente disponível de padrões para a dignidade e a integridade de todos os seres humanos" (HAMELINK, 2005, p. 105), justifica-se adotá-los como ponto de partida para a investigação do aparecimento de novos direitos relacionados à sociedade da informação.

Praticamente ao mesmo tempo em que a sociedade da informação despontava e ganhava seus contornos, os direitos pertinentes ao homem e à sua vida em sociedade experimentaram, em termos de normatividade, um avanço nunca antes visto, fruto de um longo e acidentado processo de afirmação histórica (COMPARATO, 2005). Nesse movimento, representou um divisor de águas a Declaração Universal dos Direitos do Homem (DUDH) (NAÇÕES UNIDAS, 1948), promulgada pela Assembleia Geral da ONU três anos após o fim da II Guerra Mundial, num momento em que as atrocidades cometidas durante o conflito ainda eram parte da memória coletiva recente. A série de direitos proclamados no documento, fundados "na dignidade e no valor da pessoa humana e na igualdade de direitos dos homens e das mulheres" formou o núcleo daquilo que se conhece como "direitos humanos".

Naquela época, escreve Sengupta (2002), havia-se formado um consenso sobre a unidade entre os direitos civis e políticos (arts. $1^{\circ}$ a 21 da DUDH) e os direitos econômicos, sociais e religiosos (arts. 22 a 28 da DUDH), dentro do arcabouço dos direitos humanos. O advento da Guerra Fria, na década de 1950, selou o fim do consenso sobre a integração entre esses dois grupos de direitos, tendo por resultado a promulgação de tratados internacionais apartados relativos de cada um deles no final da década de 1960, e ambos começaram a ser implementados no final dos anos 1970. 
Passaram-se muitos anos, deliberações e negociações, além do arrefecimento da Guerra Fria, para que os direitos humanos fossem novamente reputados como integrados e indivisíveis. Tal fato se consumou na Declaração sobre o Direito ao Desenvolvimento (DDD), em cujo art. $1^{\circ}, \S 1^{\circ}$ se lê:

O direito ao desenvolvimento é um direito humano inalienável, em virtude do qual toda pessoa e todos os povos estão habilitados a participar do desenvolvimento econômico, social, cultural e político, para ele contribuir e dele desfrutar, no qual todos os direitos humanos e liberdades fundamentais possam ser plenamente realizados. (NAÇÕES UNIDAS, 1986, online, nosso grifo).

Desse extrato, pelo menos duas conclusões são possíveis: a primeira é de que o desenvolvimento tem por sujeito e também por objeto o ser humano, considerado tanto como indivíduo como em coletividade ("os povos"); dito de outra forma, é um direito que deve ser implementado por pessoas ou grupos em favor de outros e de si mesmos, exigindo para tanto ações concretas. A segunda inferência faz ver que o desenvolvimento é considerado um processo multifacetado, no qual se envolvem, no mínimo, quatro dimensões: a econômica, a social, a cultural e a política.

Apesar dos êxitos, debatia-se ainda, na ocasião, se os direitos econômicos, sociais e culturais eram, de fato, direitos humanos e, caso o fossem, se seriam justificáveis e essenciais. Como resultado dessa disputa, a implementação dos direitos atinentes ao desenvolvimento sofreu grande atraso, muito devido ao único voto contrário recebido pela DDD quando de sua aprovação - dos EUA, que repetiram a atitude tomada quando da aprovação da DUDH, em 1948.

Apenas após o desmantelamento do bloco socialista foi possível retomar o consenso acerca da unidade dos direitos humanos e do reconhecimento do direito ao desenvolvimento como direito humano fundamental. A Declaração e Plano de Ação de Viena (VDPA, na sigla em inglês), resultante da Segunda Conferência Mundial da ONU sobre Direitos Humanos, com o assentimento dos EUA, veio reafirmar que

I.10 [...] o direito ao desenvolvimento, como estabelecido na Declaração dos Direitos ao Desenvolvimento, como um direito universal e inalienável e parte integral dos direitos humanos fundamentais. Como afirma a Declaração sobre o Direito ao Desenvolvimento, a pessoa humana é o sujeito central do desenvolvimento [...]. (NAÇÕES UNIDAS, 1993, online, nosso grifo). 
Contudo, como reconhecem as próprias Nações Unidas, um dos muitos desafios para a consecução do direito ao desenvolvimento na sociedade da informação é conciliar progresso científico e tecnológico com o bem-estar humano ou, ao menos, a não violação aos demais direitos humanos.

I.11 [...] Todas as pessoas têm direito a usufruir dos benefícios decorrentes do progresso científico e suas aplicações. A Conferência Mundial sobre Direitos do Homem refere que alguns progressos, nomeadamente no campo das ciências biomédicas e da vida e da tecnologia de informação, podem ter consequências potencialmente adversas na integridade, na dignidade e nos direitos humanos do indivíduo, e apela à cooperação internacional para garantir o respeito cabal dos direitos do homem e da dignidade da pessoa humana nesta área de preocupação universal. (NAÇÕES UNIDAS, 1993, online, nosso grifo).

De tudo o que foi exposto até agora, pode-se fixar os seguintes pontos: (1) a sociedade da informação é caracterizada por diversas categorias, as quais, por seu turno, podem ser reunidas em grupos (econômico, das relações de trabalho, educacional, de visão de mundo, de interconectividade, etc.); (2) a informação ocupa posição nuclear na sociedade da informação; (3) o direito ao desenvolvimento é reconhecido como um direito humano múltiplo, que contempla ao menos quatro dimensões: econômica, social, política e cultural; e (4) a pessoa humana é o sujeito central do desenvolvimento.

Há, sem dúvida, várias formas de se observar a implementação do direito ao desenvolvimento na sociedade da informação. Uma delas consiste na tentativa de mapear as categorias da sociedade da informação às dimensões do direito ao desenvolvimento, e identificar se há correspondência entre o objeto central de uma e de outro.

Reagrupar as categorias da sociedade da informação identificadas por Karvalics (Quadro 1) dentro das quatro dimensões do direito ao desenvolvimento é algo perfeitamente plausível e exequível, mesmo admitindo que uma dada categoria pode estar inserida em mais de uma dimensão ao mesmo tempo. O mesmo não se pode dizer em relação aos objetos centrais: aqui, há uma clara oposição, informação e ser humano disputando o mesmo lugar. Desse conflito, emergem dois movimentos: a sociedade da informação em seu esforço de reduzir o ser humano a mera informação, e, no sentido contrário, o ser humano na tentativa de se apoderar da informação e a utilizar em benefício de seu desenvolvimento. 
Os efeitos do primeiro movimento já foram explanados na seção anterior, quando se descreveram as características da sociedade da informação. Resta, portanto, ver com mais detalhes o que move a segunda corrente.

\section{O ACESSO À INFORMAÇÃO COMO DIREITO HUMANO}

A necessidade humana de acesso à informação foi identificada muito antes de a sociedade da informação ter se tornado o paradigma econômico vigente. $\mathrm{O}$ artigo 19 da DUDH reconheceu, já em 1948, o direito de acesso à informação como parte integrante da liberdade de opinião e expressão, assim declarando:

Toda pessoa tem direito à liberdade de opinião e expressão; este direito inclui a liberdade de, sem interferência, ter opiniões e de procurar, receber e transmitir informações e ideias por quaisquer meios e independentemente de fronteiras. (NAÇÕES UNIDAS, 1948, online, nosso grifo).

O direito de participar e usufruir do progresso científico, mais tarde reafirmado na DDD, também já vinha ali previsto: "Art. $27 . \S 1^{\circ}$. Toda pessoa tem o direito de participar livremente da vida cultural da comunidade, de fruir as artes e de participar do processo científico e de seus benefícios". Os eventuais malefícios do progresso e sua repercussão na proteção dos direitos humanos, por outro lado, só vieram à baila em 1968, pela declaração adotada na Conferência Internacional de Teerã sobre Direitos Humanos (HAMELINK, 2005, p. 107). As ressalvas quanto aos efeitos colaterais do avanço tecnológico foram, mais tarde, acolhidas na DDD, conforme já demonstrado.

Qual é, enfim, a substância do direto humano à informação? Mathiesen (2009) oferece um quadro geral a esse respeito. O primeiro ponto abordado é a questão do interesse pela informação, o qual, segundo o autor, enquadra-se em um dos três tipos seguintes: (a) o interesse expressivo, que consiste no interesse direto de emitir opinião e ter atitudes e sentimentos em assuntos de natureza pessoal ou geral, e talvez até mesmo o interesse de que essas ideias venham a influenciar o pensamento e a conduta de outras pessoas; (b) o interesse deliberativo, que diz respeito à possibilidade de revisar e obter uma compreensão mais profunda das crenças e compromissos assumidos individual e coletivamente; e (c) o interesse pelo conhecimento, tido como o interesse fundamental em conhecer as expressões do conhecimento alheio, de forma a assegurar informação confiável acerca das 
condições necessárias para buscar os próprios interesses e aspirações; em outras palavras, o bem-estar tanto de indivíduos quanto de grupos exige que as ações tomadas tenham base no melhor conhecimento disponível, um conhecimento que, com muita dificuldade, cada pessoa conseguiria construir por si mesma.

Outro aspecto salientado por Mathiesen é que o acesso à informação se configura como um direito essencialmente instrumental. Dado que os direitos humanos são interdependentes, ter acesso à informação se faz mister para que alguém esteja em condições de exercer seus demais direitos. Para tanto, a primeira informação que deve ser disponibilizada é aquela que concerne ao que são os direitos. Num segundo momento, os indivíduos procurarão saber se seus direitos estão sendo respeitados e por quais meios podem pressionar para que sejam cumpridos. Por fim, o acesso à informação é pressuposto indispensável para o exercício de uma miríade de outros direitos humanos, em particular os de natureza política.

O fato de o acesso à informação estar associado à liberdade de expressão pode levar a crer que o primeiro seja também apenas um direito de liberdade. No entanto, pondera Mathiesen (2009), a mera liberdade de acesso à informação é uma proteção deficitária para o direito à informação. A melhor compreensão que se pode ter do direito em tela é assumindo-o como um direito de natureza social que, dessa forma, obriga governos e outros setores da sociedade a fornecer à população a informação e o conhecimento que forem precisos.

\section{O ACESSO À INFORMAÇÃO NA DINÂMICA DA SOCIEDADE DA INFORMAÇÃO: O ACESSO À INTERNET COMO DIREITO HUMANO}

O advento e a dominância da sociedade da informação levaram a necessidade de acesso à informação a patamares inimagináveis no tempo em que o respectivo direito foi concebido. Essa afirmação pode ser constatada em quaisquer aspectos que se analise, seja a quantidade, a frequência ou a rapidez com que as pessoas precisam da informação.

Numa economia que, além de informacional e global, se distribui em rede (CASTELLS, 2005), poder ter acesso à maior rede já construída pelo ser humano, a Rede Mundial de Computadores - ou simplesmente Internet, para todos aqueles já íntimos dela - assume uma importância tal que, sem arriscar parecer exagerado, 
avoca a própria condição de necessidade humana. É nela que a informação circula, e, muitas vezes, é gerada.

Desde a década de 1960, as nações do então chamado "Terceiro Mundo" começaram a utilizar suas vozes e votos nos organismos internacionais, para chamar a atenção para os muitos problemas oriundos de sua evidente hipossuficiência, dentre eles sua marginalidade em termos políticos, culturais e comunicacionais (TOMLINSON, 1991). Esse movimento tomou corpo ao longo do decênio seguinte, resultando na conclamação de uma "Nova Ordem Econômica Internacional” pela Assembleia Geral das Nações Unidas, em 1974. Seguiu-se o chamado, pela UNESCO${ }^{3}$, por uma "Nova Ordem Mundial de Informação e Comunicação", para a qual foi formada uma comissão, liderada pelo irlandês Seán MacBride. O relatório (UNESCO, 1980) dessa comissão não apenas denunciou o extremo desequilíbrio no fluxo de informações entre países desenvolvidos e em desenvolvimento, como também a concentração da mídia nas mãos de poucos grupos empresariais. A contundência das denúncias contidas no relatório foi tomada, pelos Estados Unidos e pelo Reino Unido, como afronta à liberdade de imprensa e à doutrina do livre fluxo de informações. Em consequência, ambas as nações se retiraram da UNESCO (e Ihe cortaram o financiamento) até 2003 e 1997, respectivamente.

As discussões específicas no tangente ao direito de acesso à Internet tiveram início com a proposta, feita em 2001 pela Assembleia Geral das Nações Unidas, da criação de uma cúpula global a fim de discutir tópicos relativos às tecnologias de informação e comunicação (TICs). Após uma série de reuniões preparatórias, a primeira fase da Cúpula Mundial sobre a Sociedade da Informação (WSIS, na sigla em inglês) ocorreu em Genebra (Suíça), no ano de 2003, com a participação de 175 países e de agências especializadas das Nações Unidas, como a UNESCO e a $\mathrm{ITU}^{4}$. Nessa primeira reunião, foi adotada uma Declaração de Princípios (WSIS, 2003a), cujo § 48 declara o reconhecimento da importância da Internet, e também que sua governança, tão logo se constituísse uma questão central na agenda da sociedade da informação, deve ser feita de forma multilateral, transparente e

3 Acrônimo em inglês para United Nations Educational, Scientific and Cultural Organization (Organização das Nações Unidas para a Educação, a Ciência e a Cultura).

4 Acrônimo em inglês para International Telecommunication Union (União Internacional de Telecomunicações). 
democrática, com a participação de governos, do setor privado, da sociedade civil e das organizações internacionais, levando em conta a distribuição equitativa de recursos, a universalidade de acesso, seu funcionamento estável e seguro e ainda a pluralidade linguística $(\S 48)$.

Na mesma ocasião, foi adotado também um Plano de Ação, propondo, entre outros gestos concretos, que

[§ 10, alínea "d"] Os governos e outras partes interessadas deverão estabelecer pontos de acesso comunitários e públicos, fornecendo acesso de baixo custo ou gratuito aos vários recursos de comunicação, nomeadamente a Internet, a seus cidadãos. Tais pontos de acesso devem, na medida do possível, ter capacidade suficiente para prover assistência aos usuários, em bibliotecas, instituições de ensino, órgãos da administração pública, agências dos correios ou outros locais públicos, com especial ênfase nas zonas rurais e carentes, respeitando os direitos de propriedade intelectual e encorajando o uso de informações e a partilha de conhecimentos. (WSIS, 2003b, online, nossa tradução ${ }^{5}$ ).

A segunda fase da WSIS teve lugar em Túnis (Tunísia), no ano de 2005, e terminou sem consenso acerca da governança da Internet, diante da recusa, por parte dos EUA, em abandonar o controle da ICANN ${ }^{6}$. Contudo, do ponto de vista dos usuários finais, a ideia do acesso à internet como direito social, exigindo a contrapartida de governos e de setores da sociedade civil para sua efetiva consecução, já estava formada. Falta, porém, um instrumento normativo que a formalize.

Um passo decisivo nesse sentido foi dado com o relatório (NAÇÕES UNIDAS, 2011a) do Relator Especial sobre a Promoção e Proteção do Direito à Liberdade de Opinião e de Expressão do Conselho de Direitos Humanos das Nações Unidas, Frank La Rue, dirigido a este órgão por ocasião de sua $17^{\text {a }}$ sessão, em 16 de maio de 2011. Nele, o Relator Especial tece suas considerações a partir do princípio de que o acesso à Internet compreende dois aspectos: o acesso ao conteúdo nela

5 Texto original: "Governments, and other stakeholders, should establish sustainable multi-purpose community public access points, providing affordable or free-of-charge access for their citizens to the various communication resources, notably the Internet. These access points should, to the extent possible, have sufficient capacity to provide assistance to users, in libraries, educational institutions, public administrations, post offices or other public places, with special emphasis on rural and underserved areas, while respecting intellectual property rights (IPRs) and encouraging the use of information and sharing of knowledge."

6 Acrônimo em inglês para Internet Corporation for Assigned Names and Numbers (Corporação da Internet para Atribuição de Nomes e Números), órgão essencial para o funcionamento da Internet. 
hospedado e o acesso à infraestrutura física e técnica exigida para se acessar à Internet.

Ao longo do texto, fica expressa a preocupação do Relator Especial quanto a atos de poder que têm desconectado usuários da Internet de forma pontual, em momentos-chave como eleições, protestos, ou que bloqueiam o acesso aos sítios dos partidos de oposição, da mídia independente e de redes sociais - situações observadas, principalmente, no Oriente Médio e no norte da África, em especial no Egito (§ 30). A desconexão ou o bloqueio têm sido usados inclusive sob a alegação de violação de direitos de propriedade intelectual ( $\S \S 49$ e 50). Estende sua inquietude à exclusão digital, ponto em que a África é outra vez o destaque negativo (§ 61).

La Rue, outrossim, nota que estão em curso várias iniciativas ao redor do mundo com vistas a combater a exclusão digital (§ 63), inclusive no Brasil (Programa "Computador para Todos", $\S$ 64) e que alguns países economicamente desenvolvidos têm adotado legislações ou jurisprudências reconhecendo o acesso à Internet como um direito humano, como é o caso da Estônia (desde 2000), da França (desde 2009) e da Costa Rica (desde 2010). A Finlândia (desde 2009) não apenas reconhece o direito de acesso à Internet, como também estabelece que a velocidade mínima aceitável de conexão é de $1 \mathrm{Mbps}^{7}$, caracterizado como "banda larga". Relata ainda que, de acordo com uma pesquisa realizada pela rede de televisão inglesa BBC em março de 2010, 79\% dos entrevistados em 26 países acreditam ser o acesso à Internet um direito humano fundamental (§ 65).

Entre as muitas considerações e recomendações do relatório, o $§ 78$ é especialmente incisivo ao manifestar que

[...]. O Relator Especial considera que desconectar os usuários do acesso à Internet, independentemente da justificativa dada, em particular por razões de violação das leis de direitos de propriedade intelectual, é desproporcional e, portanto, uma violação ao art. $19^{8}, \S 3^{\circ}$, do Pacto Internacional sobre

7 Megabits por segundo.

8 Art. 19.[...]

$\S 2^{\circ}$. Toda pessoa terá direito à liberdade de expressão; esse direito incluirá a liberdade de procurar, receber e difundir informações e ideias de qualquer natureza, independentemente de considerações de fronteiras, verbalmente ou por escrito, em forma impressa ou artística, ou qualquer outro meio de sua escolha.

$\S 3^{\circ}$. O exercício do direito previsto no $\S 2^{\circ}$ do presente artigo implicará deveres e responsabilidades especiais. Consequentemente, poderá estar sujeito a certas restrições, que devem, entretanto, ser expressamente previstas em lei e que se façam necessárias para: 
Direitos Civis e Políticos. (NAÇÕES UNIDAS, 2011a, nossos grifo e tradução ${ }^{9}$ ).

Essa posição do Relator Especial, aliada à aprovação de seu relatório pelo Conselho de Direitos Humanos, foi tomada por setores da comunidade internacional (A HUMAN RIGHT, 2011) como um reconhecimento, por parte das Nações Unidas, do direito humano de acesso à Internet, fato que chegou a ser noticiado pela imprensa na época (KRAVETS, 2011; THURLER, 2011).

Todavia, o reconhecimento, caso se tenha dado efetivamente, foi feito de modo tácito, dando margem a questionamentos. Uma das mais contundentes opiniões contrárias é a de Vinton Cerf, reputado como um dos fundadores da Internet, atualmente um dos vice-presidentes da Google, Inc. Para ele,

[...] a tecnologia é uma facilitadora de direitos, e não um direito em si. Há um patamar muito alto para que algo seja considerado um direito humano. Dito de forma geral, ela deve estar entre as coisas de que nós, como seres humanos, necessitamos para ter uma vida saudável e significativa, como estar livres de tortura ou a liberdade de consciência. É um erro colocar qualquer tecnologia em particular numa categoria tão alta, eis que, ao longo do tempo, acabaríamos dando valor às coisas erradas. Por exemplo, houve uma época na qual ganhar a vida era extremamente difícil para quem não possuía um cavalo. Mas o direito que importa, nesse caso, é o de ganhar a vida, e não o direito a ter um cavalo. Hoje, se me fosse concedido o direito de ter um cavalo, eu não teria certeza de onde poderia colocá-lo. (CERF, 2012, online, nossa tradução ${ }^{10}$ ).

A postura de Cerf, ao mesmo tempo carregada da autoridade de quem é considerado um dos pais da Rede Mundial de Computadores (ICANN, 2001, online), pode também refletir o ponto de vista da corporação da qual ele está a serviço, uma das maiores empresas de tecnologia do mundo (FORBES, 2012, online) - e, como é

a) assegurar o respeito dos direitos e da reputação das demais pessoas;

b) proteger a segurança nacional, a ordem, a saúde ou a moral pública. (NAÇÕES UNIDAS, 1966, online).

9 Texto original: "[...] The Special Rapporteur considers cutting off users from Internet access, regardless of the justification provided, including on the grounds of violating intellectual property rights law, to be disproportionate and thus a violation of article 19, paragraph 3, of the International Covenant on Civil and Political Rights."

10 Texto original: "[...] technology is an enabler of rights, not a right itself. There is a high bar for something to be considered a human right. Loosely put, it must be among the things we as humans need in order to lead healthy, meaningful lives, like freedom from torture or freedom of conscience. It is a mistake to place any particular technology in this exalted category, since over time we will end up valuing the wrong things. For example, at one time if you didn't have a horse it was hard to make a living. But the important right in that case was the right to make a living, not the right to a horse. Today, if I were granted a right to have a horse, I'm not sure where I would put it."

R. Inter. Interdisc. INTERthesis, Florianópolis, v.10, n.2, p. 263-281, Jul./Dez. 2013 
sabido, quase sempre os interesses do capital estão em choque com a defesa dos direitos humanos. Logo, resta inconclusivo o debate sobre o acesso à Internet ser de fato um direito humano, embora o Direito Internacional pareça caminhar com firmeza nessa direção. Sinal disso é que La Rue apresentou um relatório subsequente (NAÇÕES UNIDAS, 2011b), reafirmando sua posição e acolhido, dessa vez, pela Assembleia Geral da ONU.

\section{CONSIDERAÇÕES FINAIS}

No atual estágio da sociedade humana, não é possível conceber um mundo no qual ainda se denega às pessoas o acesso aos benefícios do desenvolvimento $e$ à tecnologia da informação. Há uma íntima relação entre ambos os objetos, no sentido em que o desenvolvimento, principalmente no aspecto tecnológico, tem o condão de multiplicar as condições de produção e de acesso à informação. Concomitantemente, a informação é subsídio primário para a promoção do desenvolvimento. Nos dias atuais, grande parte desse movimento acontece na Internet (ou por sua causa, ou em sua função), de modo que tanto o direito de acesso a ela (como um direito social, que compromete o Estado e a sociedade com ações positivas para efetivá-lo) quanto a garantia de nível de serviço e de nãodesconexão passam à condição de necessidade socialmente engendrada.

O cerne da questão reside em determinar o quão básica é essa necessidade, para daí determinar se o direito de acesso à Internet cumpre os requisitos para ser reconhecido como direito humano fundamental. Tudo leva a crer que, em razão da dependência cada vez maior que o ser humano tem adquirido de consumir informações para viver bem em sociedade, esse direito está prestes a ser acolhido como tal, embora o que devesse acontecer, de fato, fosse a consecução plena do direito à informação, acessada, produzida, compartilhada e consumida por qualquer via. 


\title{
DEVELOPMENT IN THE CONTEXT OF THE INFORMATION SOCIETY AND INTERNET ACCESS AS A HUMAN RIGHT IN THE INTERNATIONAL ORDER
}

\begin{abstract}
:
This paper proposes a theoretical reflection on the question of development within the information society, comparing their categories and central objects. Starting from there, it checks what is meant as development by international organizations as well as its implications to the information society. It evaluates the changes performed to the human right to information on behalf of the dynamics of technological evolution which led to the emergence of the right to Internet access and its potential acknowledgement as a human right. Then, it examines the arguments for and against such acknowledgement and its consequences. It considers, finally, the current stage to be inconclusive, but also that it walks at a steady pace in order to embrace the right to Internet access as a human right; nevertheless, it argues that one should think of ensuring access to information broadly, through any means.

Keywords: Information Society. Development. Access to information. Right to Internet access. Human rights. International organizations.

\section{EL DESARROLLO EN EL CONTEXTO DE LA SOCIEDAD DE LA INFORMACIÓN Y EL ACCESO A INTERNET COMO DERECHO HUMANO EN EL ORDEN INTERNACIONAL}

\section{Resumen:}

Este artículo propone una reflexión teórica sobre el tema del desarrollo en la sociedad de la información, comparando sus categorías y objetos centrales. Desde ese punto de partida verifica, en la esfera de los organismos internacionales, lo que se entiende por desarrollo y sus implicaciones en la sociedad de la información. Evalúa las transformaciones que se sucedieron en el derecho humano a la información por cuenta de la dinámica de los cambios tecnológicos, las cuales dieron lugar a la aparición del derecho de acceso a Internet y de su potencial reconocimiento como un derecho humano. A continuación, examina los argumentos a favor y en contra de ese reconocimiento y sus implicaciones. Considera, en fin, que la etapa actual no es concluyente, aunque camina firmemente hacia la aceptación del derecho de acceso a Internet como un derecho humano; sin embargo, sostiene que se debería pensar en garantizar el acceso a la información en general, por cualquier medio.

Palabras-clave: Sociedad de la información. Desarrollo. Acceso a la información. Derecho de acceso a Internet. Derechos humanos. Organismos internacionales. 


\section{REFERÊNCIAS}

A HUMAN RIGHT. UN Declares Internet Access AHUMANRIGHT. 5 June 2011. Disponível em: <http://ahumanright.org/blog/2011/06/un-declares-internet-access-ahuman-right/>. Acesso em: 29 jun. 2012.

AVANCINI, Helenara Braga. Direitos humanos fundamentais na sociedade da informação. Brasília : Biblioteca Digital Jurídica - STJ, 2006. Disponível em: <http://bdjur.stj.jus.br/xmlui/bitstream/handle/2011/1937/Direitos Humanos Fundame ntais.pdf>. Acesso em: 18 jun. 2012.

CASTELLS, Manuel. A sociedade em rede. Trad. por Roneide Venancio Majer. 8. ed. São Paulo: Paz e Terra, 2005, v. 1.

CERF, Vinton G. Internet Access Is Not a Human Right. The New York Times, New York, 5 Jan. 2012, p. A25. Disponível em:

<http://www.nytimes.com/2012/01/05/opinion/internet-access-is-not-a-humanright.html>. Acesso em: 29 jun. 2012.

COMPARATO, Fábio Konder. A afirmação histórica dos direitos humanos. 4. ed. rev. e atual. São Paulo: Saraiva, 2005.

DE MASI, Domenico. O futuro do trabalho: fadiga e ócio na sociedade pósindustrial. Trad. por Yadyr A. Figueiredo. Rio de Janeiro: José Olympio, 2001.

FORBES. Global 2000 Leading Companies, 4 Apr. 2012. Disponível em: <http://www.forbes.com/global2000/\#p 1 s a0 Computer\%20Services All\%20count ries All\%20states >. Acesso em: 30 jun. 2012.

HAMELINK, C. J. Direitos Humanos para a Sociedade da Informação. In: MARQUES DE MELO, J.; SATHLER, L. Direitos à Comunicação na Sociedade da Informação. São Bernardo do Campo, SP: Umesp, 2005.

ICANN. Vita: Vinton Gray Cerf. 8 Feb. 2001. Disponível em: <http://www.icann.org/en/news/correspondence/cerf-testimony-08feb01en.htm\#Vita>. Acesso em: 30 jun. 2012.

ITU [INTERNATIONAL COMMUNICATION UNION]. Measuring the information society 2012. Geneva : International Communication Union, 2012. Disponível em: $<$ http://www.itu.int/ITU-

D/ict/publications/idi/material/2012/MIS2012 without Annex 4.pdf>. Acesso em: 14 out. 2012.

KARVALICS, László Z. Information Society - what is it exactly? (The meaning, history and conceptual framework of an expression). Budapest : Network for Teaching Information Society, 2007. Disponível em: <http://www.ittk.hu/netis/doc/ISCB eng/02 ZKL final.pdf>. Acesso em: 20 fev. 2012.

KRAVETS, David. U.N. Report Declares Internet Access a Human Right. Wired, 3 June 2011. Disponível em: <http://www.wired.com/threatlevel/2011/06/internet-ahuman-right/>. Acesso em: 29 jun. 2012. 
LAZZARATO, Maurizio; NEGRI, Antonio. Trabalho imaterial: formas de vida e produção de subjetividade. Trad. de Mônica Jesus. Rio de Janeiro : DP\&A, 2001.

MACHLUP, Fritz. The Production and Distribution of Knowledge in the United States. Princeton : Princeton University Press, 1962. Disponível em: <http://archive.org/details/productiondistri00mach>. Acesso em: 15 jun. 2012.

MATHIESEN, Key. Access to Information as a Human Right. In: ICONFERENCE, 3., 2009, Chapel Hill. Annals... Chapel Hill : University of North Carolina, 2009.

Disponível em:

<http://www.ideals.illinois.edu/bitstream/handle/2142/15236/IConf Information as a Human Right.doc.pdf?sequence=4>. Acesso em: 28 jun. 2012.

NAÇÕES UNIDAS. 1948. Assembleia Geral. Declaração Universal dos Direitos do Homem. Doc. ONU A/810, 8 dez. Disponível em:

<http://www.ohchr.org/EN/UDHR/Documents/UDHR Translations/por.pdf>. Acesso em: 27 jun. 2012.

1966. Assembleia Geral. Pacto Internacional sobre os Direitos Civis e

Políticos. Doc. ONU A/6316. Disponível em: <http://www.gddc.pt/direitoshumanos/textos-internacionais-dh/tidhuniversais/cidh-dudh-direitos-civis.html>. Acesso em: 29 jun. 2012.

1986. Assembleia Geral. Declaração sobre o Direito ao

Desenvolvimento. Doc. ONU A/RES/41/128, 4 dez. Disponível em:

$<$ http://pfdc.pgr.mpf.gov.br/atuacao-e-conteudos-de-apoio/legislacao/direitoshumanos/decl direito ao desenvolvimento.pdf>. Acesso em: 27 jun. 2012.

. 1993. Assembleia Geral. Declaração e Plano de Ação de Viena. Doc. ONU A/CONF.157/23, 12 jul. Disponível em:

$<$ http://www.direitoshumanos.usp.br/index.php/Confer\%C3\%AAncias-deC\%C3\%BApula-das-Na\%C3\%A7\%C3\%B5es-Unidas-sobre-DireitosHumanos/declaracao-e-programa-de-acao-de-viena-1993.html>. Acesso em: 28 jun. 2012.

2011. Conselho de Direitos Humanos. Relator Especial sobre a promoção e proteção do direito à liberdade de opinião e de expressão. Report of the Special Rapporteur on the promotion and protection of the right to freedom of opinion and expression, Frank La Rue. Doc. ONU A/HRC/17/27, 16 maio, $17^{\mathrm{a}}$ sessão. Disponível em: <http://daccess-ddsny.un.org/doc/UNDOC/GEN/G11/132/01/PDF/G1113201.pdf?OpenElement>. Acesso em: 29 jun. 2012.

2011. Assembleia Geral. Relator Especial sobre a promoção e proteção do direito à liberdade de opinião e de expressão. Report of the Special Rapporteur on the promotion and protection of the right to freedom of opinion and expression, Frank La Rue. Doc. ONU A/66/290, 10 ago., 66ª sessão. Disponível em: $<$ http://daccess-dds-

ny.un.org/doc/UNDOC/GEN/N11/449/78/PDF/N1144978.pdf?OpenElement>. Acesso em: 29 jun. 2012. 
SENGUPTA, Arjun. O direito ao desenvolvimento como um direito humano. Social Democracia Brasileira, mar. 2002, p. 64-84. Disponível em <http://web.archive.org/web/20041228063352/http://www.itv.org.br/site/publicacoes/ig ualdade/direito desenvolvimento.pdf>. Acesso em: 28 abr. 2012.

SILVA, Pedro Nunes Moreira da. A influência do digital na criação de espaços de aprendizagem de alta qualidade: o espaço como agente de mudança. Tese (Doutorado em Ciências da Informação) - Universidade Fernando Pessoa, Porto, 2011. Disponível em: <http://bdigital.ufp.pt/bitstream/10284/2250/1/TD.pdf>. Acesso em: 20 fev. 2012.

THURLER, Larriza. Acesso à rede é direito humano básico, diz ONU. Observatório da Imprensa, n. 645, 7 jun. 2011. Disponível em:

<http://www.observatoriodaimprensa.com.br/news/view/acesso-a-rede-e-direitohumano-basico-diz-onu>. Acesso em: 29 jun. 2012.

TOMLINSON, John. Cultural imperialism: a critical introduction. London, New York : Continuum, 1991.

UNESCO [UNITED NATIONS EDUCATIONAL, SCIENTIFIC AND CULTURAL ORGANIZATION]. Many voices, one world: towards a new more just and more efficient world information and communication order. Paris : Unesco, 1980.

WSIS [WORLD SUMMIT ON THE INFORMATION SOCIETY]. 2003. Geneva Declaration of Principles. Doc. WSIS-03/GENEVA/DOC/4-E, 12 Dec. Disponível em: <http://www.itu.int/dms pub/itu-s/md/03/wsis/doc/S03-WSIS-DOC-0004!!PDFE.pdf>. Acesso em: 29 jun. 2012.

2003. Doc. WSIS-03/GENEVA/DOC/5-E, 12 Dec. Geneva Plan of

Action. . Disponível em: <http://www.itu.int/dms pub/itu-s/md/03/wsis/doc/S03WSIS-DOC-0005!!PDF-E.pdf>. Acesso em: 29 jun. 2012.

\section{Artigo:}

Recebido em Dezembro de 2012 Aceito em Agosto de 2013 